\title{
An Evaluation on Low and Middle Strength Concretes Rebound, Upv, and Sonreb Methods
}

\author{
Muhammet Asan ${ }^{1, *}$, Hadi Abbaszadeh ${ }^{2}$, and Serkan Karatosun ${ }^{3}$ \\ ${ }^{1} \mathrm{PhD}$ Student, Faculty of Civil Engineering, Istanbul Technical University, Istanbul, Turkey \\ ${ }^{2,3}$ MS.C. Student, Faculty of Civil Engineering, Istanbul Technical University, Istanbul, Turkey \\ *Corresponding author
}

\begin{abstract}
The assessment of existing buildings and civil infrastructures become more important in recent decades. There are some methods, which was used by engineers and researchers; however, industry requires a method which needs less time for processing and cost the minimum available amount until completing process. Non-destructive test methods are an approach which could significantly decrease the amount of time, energy and cost which is used during common (destructive) coring method. There are some methods which was developed and used among NDT methods. Most common methods are Schmidt hammer rebound test and Ultrasonic puls velocity (UPV) method. In this paper, NDT measurements was implemented using these two methods for different range of concrete strength and result was shown by providing correlation of each separately. The combined SonReb method's correlations was provided also, which shows a significant increase for $r$-square values.
\end{abstract}

Keywords: Concrete, NDT, Rebound, UPV, Combined SonReb

\section{Introduction}

The reliability of reinforced concrete structures against natural disasters depends on several parameters such as the quality of materials, workmanship, design of reinforced concrete structure members and production techniques (Y1lmaz \& Avsar, 2013). One of major parameter about related issue is the quality of concrete. It is observed that the quality of concrete of RC structures is very low at the least developed and developing countries compared with developed countries. The lower limit of usable strength of concrete is $20 \mathrm{MPa}$ according to DBYBHY 2007 in Turkey. (Specification for structures to be built in disaster areas) . Despite that in Turkey, structures defined as risky have 5-15 MPa of concrete compressive strength (Er et al.,2014),(Avsar \& Tunaboyu,2014). It is crucial to designate structures with that much low concrete quality and taking required precautions.

The most reliable and safe way to evaluate current concrete quality of existing building is by taking core samples from structure and doing compressive strength test with a press in laboratory. Even though mentioned method is the safest way for the evaluation of quality of concrete, it takes too much time to perform and it is expensive methods compared with nondestructive test methods. In this paper data obtain from NDT; Schmidt hammer and Ultrasonic Pulse Velocity (UPV) was compared with compressive strength of concrete obtained from press test. Investigation done for low and mid compressive strength classes of concrete. 


\section{NDT Methods}

In this paper two types of NDT methods were used; Schmidt hammer and Ultrasonic Pulse Velocity (UPV).

\subsection{Schmidt Hammer Rebound Test}

Schmidt hammer invented by Ernst Schmidt at 1948 in order to demonstrate surface stiffness by using "rebound" principle (Kolek, 1969). Schmidt hammer does weight $1.8 \mathrm{~kg}$ approximately.

Figure 1: Schmidt hammer process (Malhotra,2004)

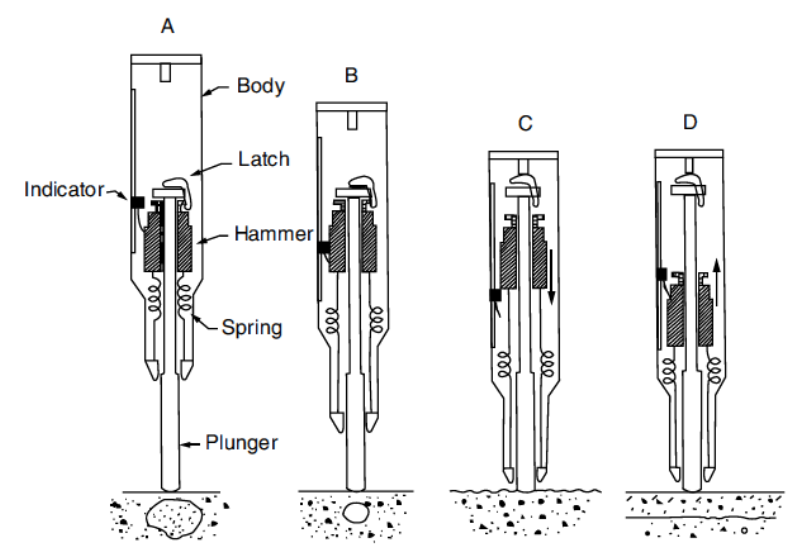

When Schmidt hammer is pressed against the concrete surface, the spring trapped in the hammer is fixed by the latch and a number is specified referring to the mechanical properties of the surface applied. The basic understanding of the Schmidt hammer is based on the wave propagation principle. When the hammer is pressed, a wave propagates through the plunger on the surface. The reaction force generated on the surface also sends the reflected wave to the plunger. The rebound numbers in the hammer is related to the ratio of these two wave amplitudes to each other (Akashi \& Amasaki, 1984).

The surface to which the Schmidt hammer method is applied must be cleaned. Ten readings should be made on the sample at intervals of at least $20 \mathrm{~mm}$ and they should not be approached more than 40-50 $\mathrm{mm}$ to the edges of the surfaces (Ilhan, 2000).

The Schmidt method is a simple, easy and inexpensive way to determine the pressure strength of concrete. However, there are many factors that affect the test result. For example; the geometry of the sample, the roughness of the surface, the age of the sample, the amount of moisture on the surface and in the sample, the aggregate and cement properties (Malhotra,2004).

The principles of Schmidt hammer test is available in the ASTM C 805: Standard Test Method for Rebound Number of Hardened Concrete.

\subsection{Ultrasonic Pulse Velocity (UPV)}

Ultrasonic pulse velocity test does not have a direct relation with compression strength of concrete. Although it is known that there is correlation between density and compressive strength of concrete. In most cases compressive strength of concrete increases as there is an increase in density of concrete. If decrease occurs in w/c ratio the amount of capillary pores in concrete would decrease. Thus, if the amount of capillary pores decrease, the receiving time of 
sound waves between two probes of UPV device would decrease.

Ultrasonic pulse velocity test: Measurement of time which sound waves generated by the probes propagate through the concrete. Sound waves generated by probs transfers through the concrete with materials such as grease oil etc.

A clock start running as the pulse movement starts on the probes. Clock stops when the first wave hits the probe and receiving time is measured. The wave speed is reached by the ratio of the distance traveled by receiving time of waves (IAEA, 2002).

Figure 2: Ultrasonic Pulse Velocity (UPV) device

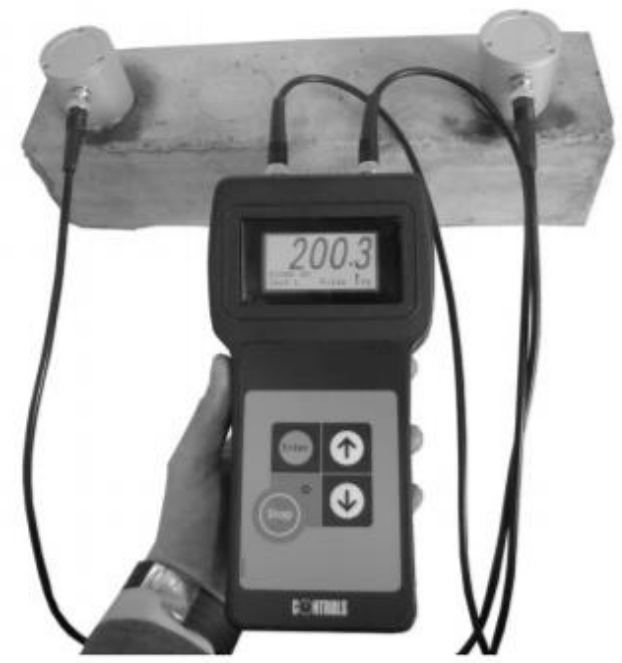

Factors affecting ultrasonic pulse velocity results are aggregate properties, cement type, admixtures, and maturity of concrete (Naik et al., 2004).

Ultrasonic pulse velocity test methodology is designated in ASTM C 597.

\section{Experimental section`s Studies}

In this study, concretes were divided into two groups as low and medium in terms of compressive strength. Totally 12 different concrete mixture designs were obtained. It is aimed to gain concretes which have lower than $16 \mathrm{MPa}$ compressive strength capacity through six of these mixture designs and also concretes which have compressive strength between 16 and 40 $\mathrm{MPa}$ with other six mixtures. $16 \mathrm{MPa}$ compressive strength is preferred regarding that $16 \mathrm{MPa}$ is found lowest strength capacity at 'TS 500: Requirements for design and construction of reinforced concrete structures' which is referenced in concrete mixture design (TS 500, 2000).

Abrams' Law method is used while determining concrete mixture designs since there is no standard for concretes which have lower than $16 \mathrm{MPa}$ strength capacity (Nagaraj \& Banu, 1996).

It is mentioned above aggregate properties, cement type, and admixtures have an influence on non-destructive testing methods. For this reason, same type of cement and admixtures are included in all mixtures. Beside, type and mixture ratio are stable in all concretes. Only the 
amount of water and cement altered to access different compressive strength. Quantities of aggregates which were used in all mixtures are shown in Table 1.

Table 1: Types, amounts and mixture ratios of aggregates

\begin{tabular}{ccc}
\hline $\begin{array}{c}\text { Type of } \\
\text { aggregates }\end{array}$ & $\begin{array}{c}\text { Mixture } \\
\text { Ratio }(\%)\end{array}$ & $\begin{array}{c}\text { Amount per 1 } \\
\mathrm{m}^{3} \text { concrete }(\mathrm{kg})\end{array}$ \\
\hline Natural Sand & 23 & 423 \\
Crushed Sand & 28 & 527 \\
Crushed Stone 1 & 26 & 495 \\
Crushed Stone 2 & 23 & 439 \\
\hline
\end{tabular}

While determining mixture ratios of aggregates, TS 500 standards are referenced.

Figure 3: Aggregate grading curves according to TS 500 standard

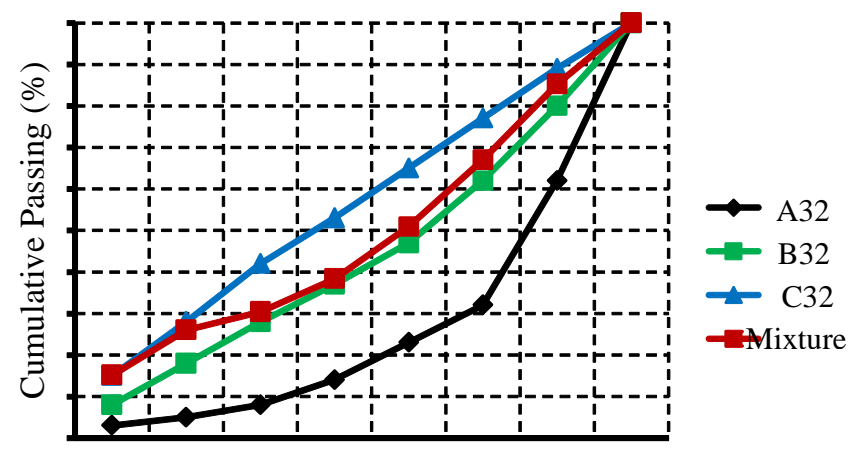

Sieve opening size $(\mathrm{mm})$

The lowest cement dosage in concrete is specified as $300 \mathrm{~kg}$ by TS 500 . However in this study, $300 \mathrm{~kg}$ is taken the highest cement dosage and it is reduced gradually to attain lowstrength concretes. The lowest cement dosage which is used in mixtures is $106 \mathrm{~kg}$.

Group A represents medium-strength concretes and Group B low-strength. Production codes are determined based on cement dosage of concrete.

\section{Results}

Five cube specimens of $15 \times 15 \times 15 \mathrm{~cm}$ in size was produced from each mixture designs. After they removed from the mold, these specimens are cured in water for 28 days. Then, specimens are air-seasoned (left to dry in open air) for 1-2 days.

Firstly, Schmidt Hammer Test is experimented to samples. Totally, 24 rebound numbers are recorded from two opposing surfaces of specimens.

In the sequel of Schmidt Hammer Test, Ultrasonic Pulse Velocity (UPS) Test performed on concretes. UPS values are obtained by settling probes on opposing surfaces of cube samples.

Finally, specimens were loaded on mangle in stable $10 \mathrm{kN} / \mathrm{s}$ loading speed and broken to get their press strength. 


\subsection{Correlations; Schmidt Hammer Rebound Number vs. Compressive Strength}

In this section the correlations between rebound number and both low-strength and middlestrength concrete compressive strength was shown and discussed based on data dispersion.

Figure 4: Correlation; rebound numbers vs. compressive strength of low-strength concrete

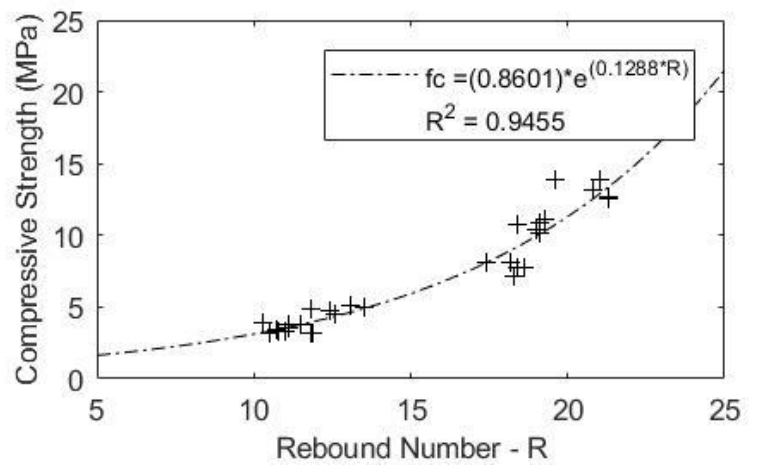

Figure 5: Correlation; rebound numbers vs. compressive strength of middle-strength concrete

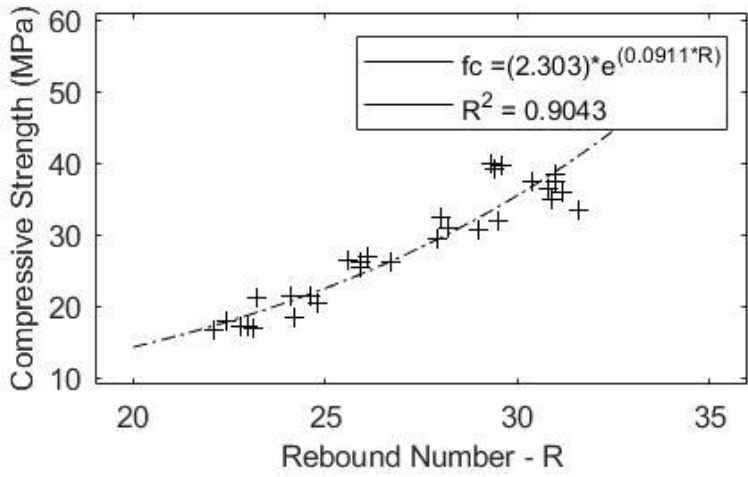

Figure 6: Correlation; rebound numbers vs. compressive strength of all data

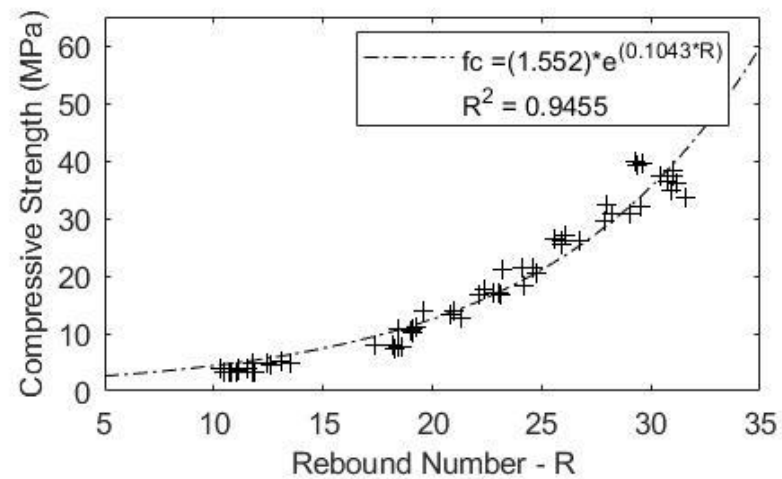

Data compaction was illustrated in Fig. 4 for low-strength concrete and the related power correlation was drawn for the compressive strength and rebound number data, it is observed that data was so close to the trend curve (correlation curve) and it is proven by the high value of $r$-square value for this correlation. Figure 5 shows the same correlation for middle-strength concrete data and the intended data and measurements correlations; however, based on r-square value and the observation it is clearly obvious that data was dispersed a bit higher than low- 
strength concrete from correlation curve. Figure 6 has just demonstrates the same study for summation of both previously mentioned data and study all data in one correlation curve, it shows that summation of both data dose not decrease the accuracy of correlation based on comparing r-square values for each set.

\subsection{Comparison of Ultrasonic Pulse Velocity and Compressive Strength}

Figure 7: Correlation; UPVs vs. compressive strength of low-strength concrete

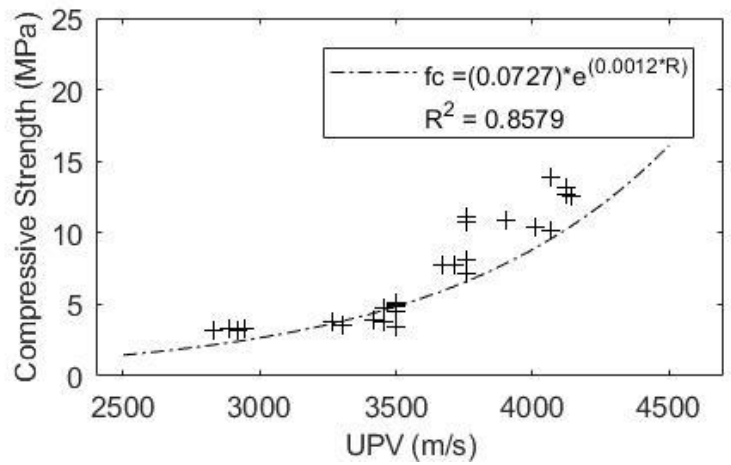

Figure 8: Correlation; UPVs vs. compressive strength of middle-strength concrete

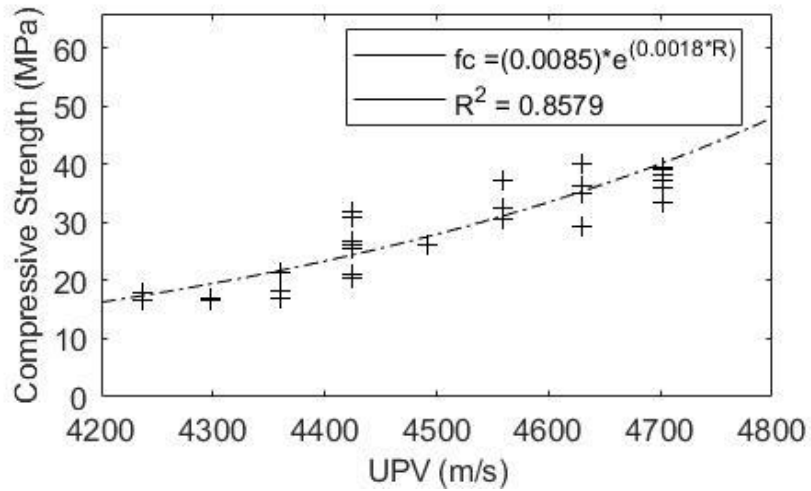

Figure 9: Correlation; UPVs vs. compressive strength of all samples

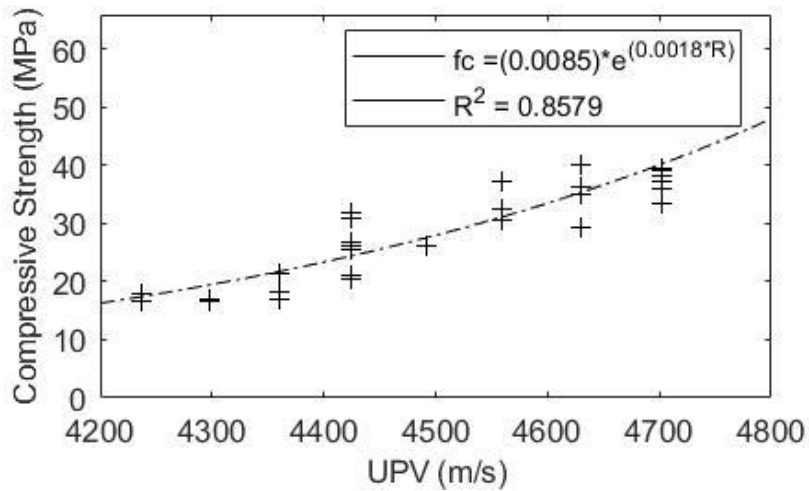

Data dispersion, correlation curves and related data`s r-square values for low-strength concrete in Fig. 7, middle-strength concrete in Fig. 8, and summation of both intended data as all data in 
Fig. 9 versus ultrasonic pulse velocity was obtained almost same and there is literally no different among them based on previously mentioned parameters.

\subsection{Correlations; Combined (rebound and UPV) vs. compressive strength}

Common combined SonReb method was used to evaluates and obtain R-square value using both rebound numbers and UPV values which significantly developed using this methods.

Figure 10: Combined Correlation; Rebound numbers and UPVs vs. compressive strength of low-strength concrete

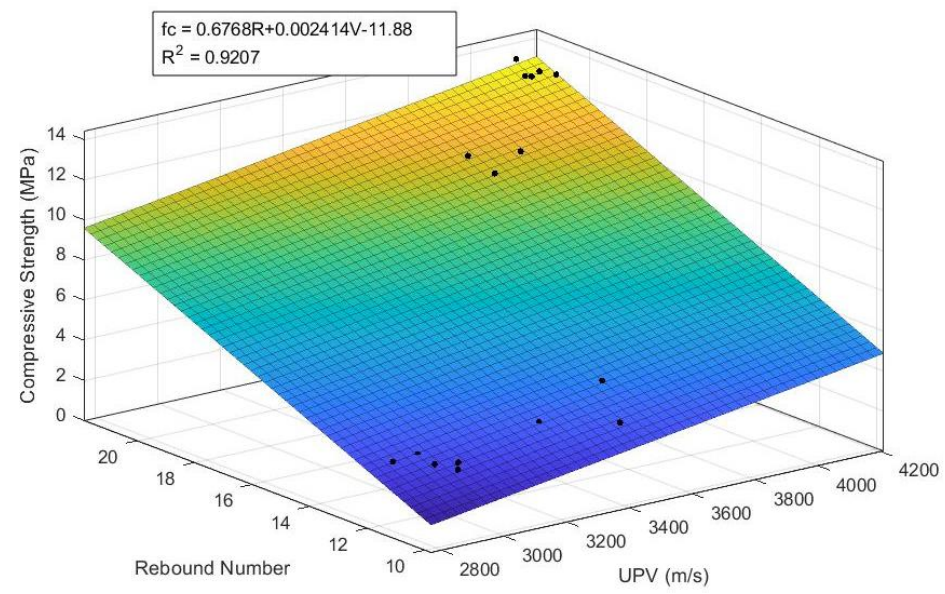

Figure 11: Combined Correlation; Rebound numbers and UPVs vs. compressive strength of middle-strength concrete

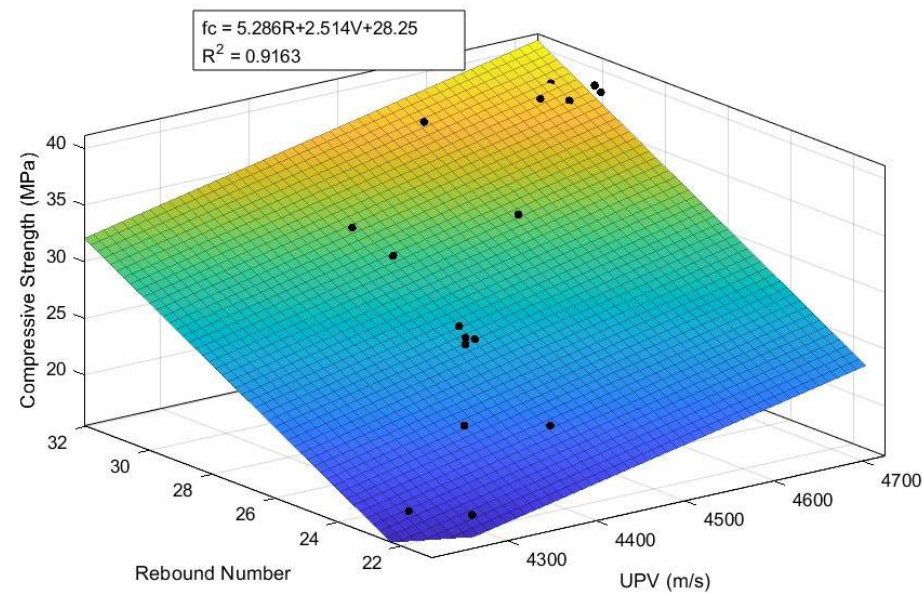


Figure 12: Combined Correlation; Rebound numbers and UPVs vs. compressive strength of all samples

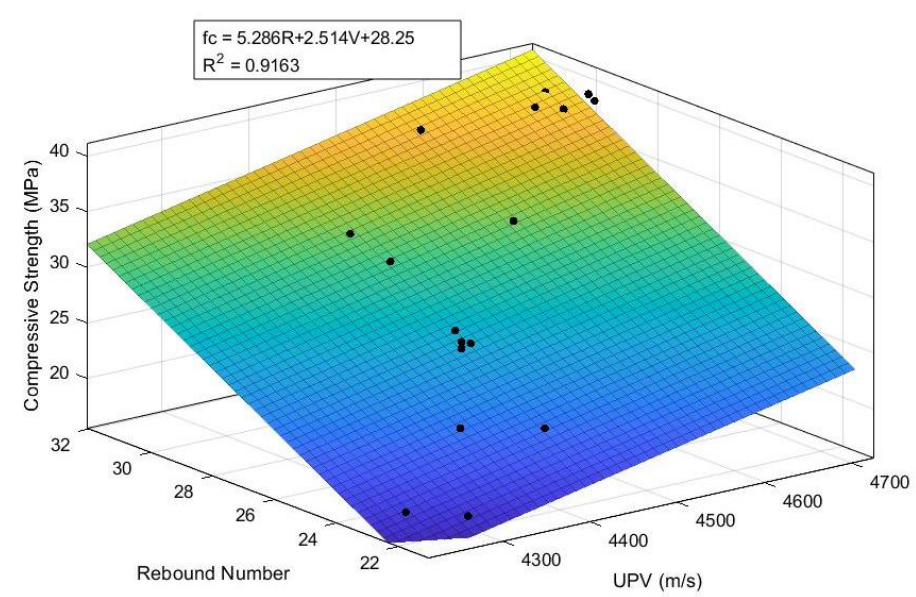

\section{R-square Value Comparison}

R-square values was obtained for 5 various equation types (Linear, Polynomial 2nd, Polynomial 3rd, Power, and Exponential) and was listed in Table 2-4. As it is observed in Table 2-4 the results are near 1; however, the result for poly. 3rd and power equations are higher compared obtained R-square value for other equations.

Table 2: Correlation equations and $R$-square values for rebound test measurements

\begin{tabular}{|c|c|c|}
\hline NDT Method & Correlation Equation & $\mathbf{r}^{2}$ \\
\hline \multicolumn{3}{|l|}{ Rebound } \\
\hline \multirow[t]{5}{*}{ Low } & $F=0.886 R-6.461$ & 0.9060 \\
\hline & $F=0.07044 R^{2}-1.31 R-9.518$ & 0.9315 \\
\hline & $F=0.001799 R^{3}-0.01645 R^{2}+0.05135 R+2.649$ & 0.9317 \\
\hline & $\mathrm{F}=0.02337 \mathrm{R}^{2.067}$ & 0.9230 \\
\hline & $\mathrm{F}=0.8601 \exp (0.1288 \mathrm{R})$ & 0.9455 \\
\hline \multirow[t]{2}{*}{ Middle } & $\mathrm{F}=2.416 \mathrm{R}-37.16$ & 0.8980 \\
\hline & 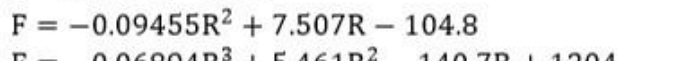 & $\begin{array}{l}0.9054 \\
\text { ก.0วn? }\end{array}$ \\
\hline NDT Method & Correlation Equation & $\mathbf{r}^{2}$ \\
\hline \multicolumn{3}{|l|}{ UPV } \\
\hline Low & $\begin{array}{l}F=3.391 \mathrm{~V}+7.24 \\
F=1.217 \mathrm{~V}^{2}+3.87 \mathrm{~V}+6.064 \\
F=-0.7903 \mathrm{~V}^{3}+0.7572 \mathrm{~V}^{2}+5.382 \mathrm{~V}+6.207 \\
\mathrm{~F}=(2.401 \mathrm{e}-18) \mathrm{V}^{5.183} \\
\mathrm{~F}=0.0085 \exp (0.0018 \mathrm{~V})\end{array}$ & $\begin{array}{l}0.8010 \\
0.9063 \\
0.9247 \\
0.8878 \\
0.8239\end{array}$ \\
\hline Middle & $\begin{array}{l}F=0.04812 \mathrm{~V}-188 \\
F=-0.5585 \mathrm{~V}^{2}-7.311 \mathrm{~V}+28.79 \\
F=-1.226 \mathrm{~V}^{3}-1.071 \mathrm{~V}^{2}+9.407 \mathrm{~V}+29.34 \\
F=(1.225 \mathrm{e}-26) \mathrm{V}^{7.488} \\
\mathrm{~F}=0.0727 \exp (0.0012 \mathrm{~V})\end{array}$ & $\begin{array}{l}0.8353 \\
0.8389 \\
0.8509 \\
0.8178 \\
0.8579\end{array}$ \\
\hline All & $\begin{array}{l}\mathrm{F}=2.416 \mathrm{~V}-37.16 \\
\mathrm{~F}=-0.09455 \mathrm{~V}^{2}+7.507 \mathrm{~V}-104.8 \\
\mathrm{~F}=1.176 \mathrm{~V}^{3}+6.293 \mathrm{~V}^{2}+12.39 \mathrm{~V}+12.29 \\
\mathrm{~F}=(1.219 \mathrm{e}-25) \mathrm{V}^{7.215} \\
\mathrm{~F}=0.01429 \exp (0.001681 \mathrm{~V})\end{array}$ & $\begin{array}{l}0.8980 \\
0.9054 \\
0.9565 \\
0.9531 \\
0.9547\end{array}$ \\
\hline
\end{tabular}


Table 4: Correlation equations and R-square values for Combined SonReb method

\begin{tabular}{llr}
\hline NDT Method & Correlation Equation & $\mathbf{r}^{2}$ \\
\hline $\begin{array}{ll}\text { SonReb } \\
\text { low }\end{array}$ & $\mathrm{F}=0.6768 \mathrm{R}+0.002414 \mathrm{~V}-11.88$ & 0.9207 \\
& $\mathrm{~F}=-1.819 \mathrm{R}-0.0046 \mathrm{~V}+0.0059 \mathrm{R}^{2}-0.0006 \mathrm{RV}-1.157 \mathrm{e}-07 \mathrm{~V}^{2}+17.6$ & 0.9494 \\
middle & $\mathrm{F}=5.286 \mathrm{R}+2.514 \mathrm{~V}+28.25$ & 0.9163 \\
& $\mathrm{~F}=4.83 \mathrm{R}-2.73 \mathrm{~V}+0.5083 \mathrm{R}^{2}-4.121 \mathrm{RV}+3 \mathrm{~V}^{2}+28.46$ & 0.9329 \\
& & \\
All & $\mathrm{F}=13.69 \mathrm{R}-2.011 \mathrm{~V}+17.74$ & 0.9219 \\
& $\mathrm{~F}=7.968 \mathrm{R}+5.03 \mathrm{~V}-1.252 \mathrm{R}^{2}+7.63 \mathrm{RV}-2.035 \mathrm{~V}^{2}+13.81$ & 0.9775 \\
\hline
\end{tabular}

Correlation equations (regressions) for rebound measurements, ultrasonic pulse velocity measurements, and combined method was derived and demonstrated with their intended rsquare values in Table 2, 3, and 4 respectively. The improvement in $r$-square value by increasing the degree of equation was obtained based on the intended equation and their r-square values. In addition, it was find out that combined method could significantly increase the r-square value of the analyzed data using couple set of data (rebound number and UPV measurements) versus one set (compressive strength).

\section{Conclusion}

The importance of NDT methods increased in recent years due to their less time requirement and cost which should be spend to a test.

Rebound tests using standard Schmidt hammer and Ultrasonic Pulse Velocity (UPV) are two common NDT measurements which is used widely by researchers and engineers.

In this paper, due to lack of knowledge about low-strength concrete the two above mentioned measurements was implemented for both low and middle strength concrete and their related correlations with compressive strength which was measured in laboratory was provided.

Combined SonReb method correlation using Rebound and UPV values simultaneously versus compressive strength was provided for each low and middle strength concretes also which shows the effect of this method by remarkable increase in r-square values. 


\section{References}

[1] Y1lmaz N., Avsar Ö., Structural Damages of the May 19, 2011 Kütahya - Simav Earthquake in Turkey, Natural Hazards, 69 (1), 981-1001, 2013..

[2] DBYBHY 2007. Specification for Buildings to be built in Disaster Areas (in Turkish), Ankara: Republic of Turkey, Ministry of Public Works and Settlement.

[3] Er Ş.B., Aykaç S., Can H., Behaviour of Reinforced Concrete Weak Column-Beam Connections, Journal of the Faculty of Engineering and Architecture of Gazi University, 537-547, 2014.

[4] Avşar Ö., Tunaboyu O., Influence of Structural Wall on the Seismic Performance of RC Buildings during the May 19, 2011 Simav, Turkey Earthquake, ASCE Journal of Performance of Constructed Facilities, pg. 1-9, 2014.

[5] Kolek, J. Non-destructive testing of concrete by hardness methods. London: Institute of Civil Engineers. 1969.

[6] Akashi, T., \& Amasaki, S. Study of the Stress Waves in the Plunger of a Rebound Hammer at the Time of Impact. Detroit: American Concrete Insitute. 1984.

[7] İlhan, İ. What does the Schmidt Hammer do?, TMH-Turkisn Engineering News. Issue 410, pp. 26-28, 2000

[8] Malhotra, V. (2004). Surface Hardness Methods. In V. Malhotra, \& N. Carino, Handbook on Nondestructive Testing of Concrete (pp. 1-9). New York: CRC Press.

[9] IAEA, Guidebook on non-destructive testing of concrete structures, pp. 100, Vienna, 2002.

[10] Naik, T., Malhotra, V., \& Popovics, J. (2004). The Ultrasonic Pulse Velocity Method. In V. Malhotra, \& N. Carino, Handbook on Nondestructive Testing of Concrete (pp. 8497). New York: CRC Press.

[11] TS 500, Requirements for design and construction of reinforced concrete structures (in Turkish), Ankara: Republic of Turkey, Ministry of Public Works and Settlement, 2000.

[12] Nagaraj, T.S. \& Banu, Z. (1996). Generalization of Abrams' Law Department of Civil Engineering Indian Institute of Science, Bangalore, INDIA

[13] ASTM Standard, C597, 'Standard Test Method for Pulse Velocity Through Concrete', ASTM International, West Conshohocken, PA, 2016, DOI: 10.1520/C0597-16

[14] ASTM Standard, C805, 'Standard Test Method for Rebound Number of Hardened Concrete', ASTM International, West Conshohocken, PA, 2013, DOI: 10.1520/C0805-13 